\title{
ICU follow-up clinic at RLI
}

Dr Kumar's article on an important cause of morbidity after critical illness is a challenge to all of us who practice in the intensive care environment to be aware of what happens when our patients are discharged from the service. We would like to make some observations on how we at the RLI see the problems.

Critical illness is a multisystem disorder with its own unique sequelae. It can take up to a year to recover from even a short admission to ICU. Patients who have required mechanical ventilation often have shortness of breath for many months after discharge, muscle weakness is almost ubiquitous amongst this population and can severely limit normal activities; and psychological symptoms are common.

Since we set up a specialist follow up clinic in 2007 we have invited all patients who have spent four or more days on ICU to attend; plus anyone who is referred to us from other specialties for concerns relating to ICU admission,

We see patients at three months following their discharge from ICU, and allow 30 minutes for each appointment. Initially we discuss the reasons for admission to ICU, and the treatment that was received, as patients often have little recollection of their time in the unit. Many patients have received sedative medication, and critical illness itself often results in neurological impairment. We then explore specific issues which are common after ICU admission: respiratory symptoms, muscle weakness and its effect on daily activities, changes in sense of taste and appetite, weight loss, and skin, hair and nail changes. Then we explore specific psychological concerns including recollection, delusional memories, nightmares and sleep disturbance.

The clinic is not well resourced: it was initially run jointly by a consultant in intensive care medicine and an advanced nurse practitioner, however funding was lost for the consultant session and for the last few years the clinic has been nurse-led with medical input sporadically or for advice. We do not yet have access to formal psychological counselling but we look forward to being able to utilise such services for the commonly reported psychological symptoms. However, what we are able to do is offer reassurance to patients that what they are experiencing is to be expected, and will get better with time. Having the opportunity to talk about their admission in detail is often enough in itself: once the patient is able to understand the reasons that they are unable to get upstairs or do their normal weekly shop they can appreciate how far they have come since their critical illness and understand that rehabilitation will be prolonged.

Dr Rachel Markham, Consultant in Anaesthetics and Intensive Care Medicine

Mel Woolfall, Advanced Nurse Practitioner Acute Care / Resuscitation Lead

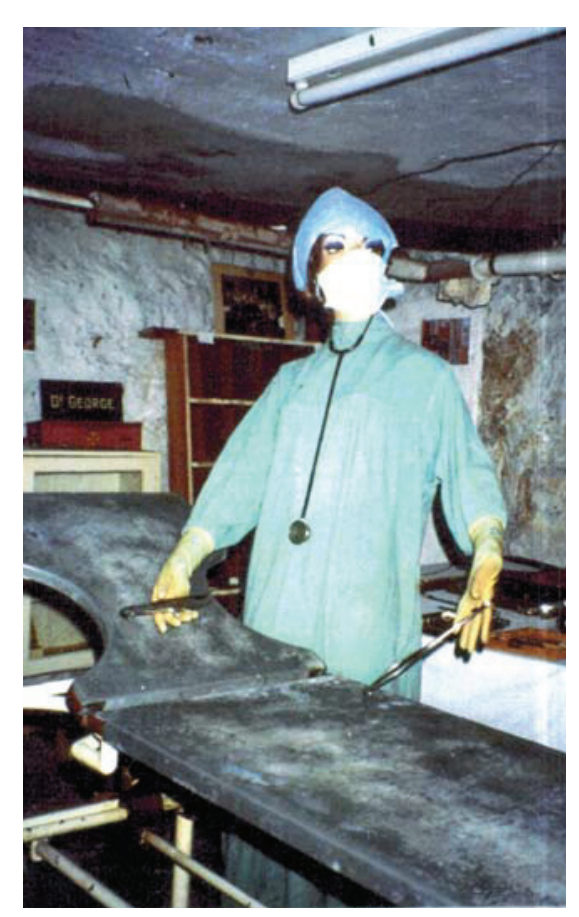

Who is this woman and where is she?

\section{How did she come to scare a member of the Lancaster Police?}

\section{If you think you know, or don't know, please contact any of the undernamed (all members of "The Lancaster Medical Museums Group").}

\section{We are all eager to have more people join us.}

Bryan Rhodes (Consultant Orthopaedic Surgeon - email: mrbrhodes@gmail.com)

Miles Rucklidge (retired Consultant Anaesthetist - email: miles@rucklidge.com)

Peter Dyer (Consultant Dental Surgeon - email: peter.dyer@mbht.nhs.uk)

Valerie Anderson (retired Hospital Specialist - phone: 0 I524-67|25)

John Carne (retired G.P. - email: john.carne@talktalk.net) 